\title{
AUTOSOMAL REARRANGEMENT IN Gryllus assimilis FABRICIUS, 1775 (ORTHOPTERA, GRYLLIDAE)
}

\author{
Edison Zefa
}

\begin{abstract}
Gryllus assimilis L. has a karyotype of $2 n=29$ (X0, male) and 30 (XX, female). The above karyotype was encountered along with another in which $2 n=28$ (X0, male) and $2 n=29$ (XX, female) in a population from the outskirts of Rio Claro city (São Paulo State, Brazil). Of eight specimens studied, five had the heterozygous karyotype involving a translocation and three had the basic karyotype. There were no individuals homozygous for the rearrangement. The heterozygous karyotype was the result of a chromosomal rearrangement between chromosome pairs 6 and 10, both of which were initially submetacentric. The members of the sixth pair normally have two constrictions in the small arm, with a satellite at the chromosome tip. The chromosome of the tenth pair involved in the translocation was generally submetacentric and probably underwent a pericentric inversion which transported the centromere to a subterminal position before being translocated. In this case, the long arm of the inverted chromosome of the tenth pair was translocated with the satellite of a member of the sixth pair.
\end{abstract}

\section{INTRODUCTION}

Many populations of orthopterans show intraspecific chromosomal variations. The main rearrangements are inversions, reciprocal translocations, centric fusion and fission, some of which involve the sex chromosomes. The interpretation of these rearrangements is relatively easy because of the large size and low number of chromosomes in this group of insects.

The genus Gryllus comprises nearly 70 species, 22 of which have already been studied cytologically. The karyotype varies from $2 \mathrm{n}=11$ (X0, male) in Gryllus minor Shir. to $2 \mathrm{n}=29$ (X0, male) in several other species. The sex determination mechanism is X0 in males and XX in females, with the $\mathrm{X}$ chromosome generally being metacentric and the largest of the set.

Baumgartner (1904) was the first to show that the karyotype of G. assimilis was $2 \mathrm{n}=29$ (male). The present work analyzed the karyotype of G. assimilis and showed that while some individuals have the chromosome number reported by Baumgartner (1904) others have a heterozygous chromosomal arrangement.

\section{MATERIAL AND METHODS}

The specimens here studied were collected from grassland and lawns on the university campus (UNESP, Rio Claro) and identified as G. assimilis using morphological and bioacoustic parameters (Weissman et al, 1981). Eight individuals were studied, and included three offspring from a single female.

Cytological preparations were obtained from tes-

Departamento de Biologia, Instituto de Biociências, Universidade Estadual Paulista (UNESP), Campus de Rio Claro, Caixa Postal 199, 13506-900 Rio Claro, SP, Brasil. E-mail: edzefa@life.ibrc.unesp.br tes, ovaries and ceca. Some specimens were injected with a $0.05 \%$ aqueous solution of colchicine and the tissues then dipped in a hypotonic solution of sodium citrate $(0.075$ M) prior to fixation in Carnoy I fixative. After at least one hour in the fixative, the cells were macerated in $45 \%$ acetic acid and squashed in a drop of $0.5 \%$ lacto-acetic orcein. The chromosome morphology was defined as described by Guerra (1986).

\section{RESULTS}

Five specimens, two adult males and three offspring of a single female (one adult male, one adult female and a pre-adult male), had rearranged karyotypes with $2 n=28$ (27 autosomes and one X chromosome) and $2 n=29$ (27 autosomes and two $\mathrm{X}$ chromosomes). The karyotype of these specimens consisted of three pairs of metacentric chromosomes (pairs 1, 8 and 9), nine pairs of acrocentrics $(2,3,4,5,7,11,12,13$ and 14), a metacentric X chromosome and a trivalent formed by three morphologically different chromosomes. One of the chromosomes in the trivalent was a large submetacentric with two secondary constrictions in the long arm (Figure 1B, horizontal arrow); the second was a medium-sized submetacentric with two secondary constrictions in the short arm, the distal one of which left a satellite at the chromosome tip (Figure 1B, vertical arrow), and the third was a small submetacentric element (chromosome 10) (Figure 1A, B).

Three adult males had normal karyotypes with $2 \mathrm{n}$ $=29, \mathrm{X} 0$; pairs 1, 8, 9 and $\mathrm{X}$ were metacentrics, 6 and 10 were submetacentrics and the remaining were acrocentrics. The sixth pair showed structural variations in the small arm and had secondary constrictions caused by differences in the length of the stretching segment of the constriction. In the pre-adult male, several cells in metaphase I were observed with 12 bivalents, one trivalent and an X chromosome (Figure 1C). 


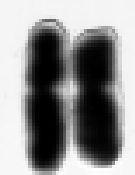

1
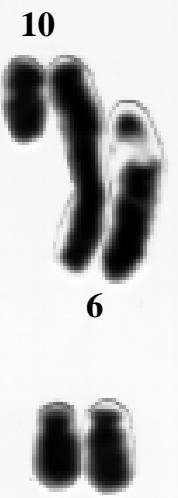

11

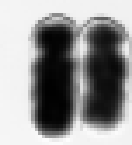

2

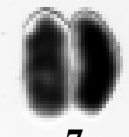

7

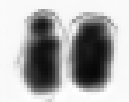

12

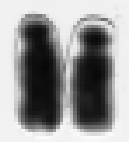

3

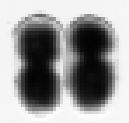

8

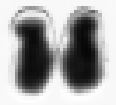

13

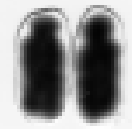

4

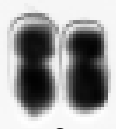

9

14

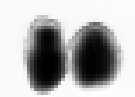

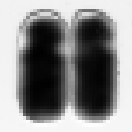

5

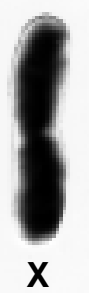

A
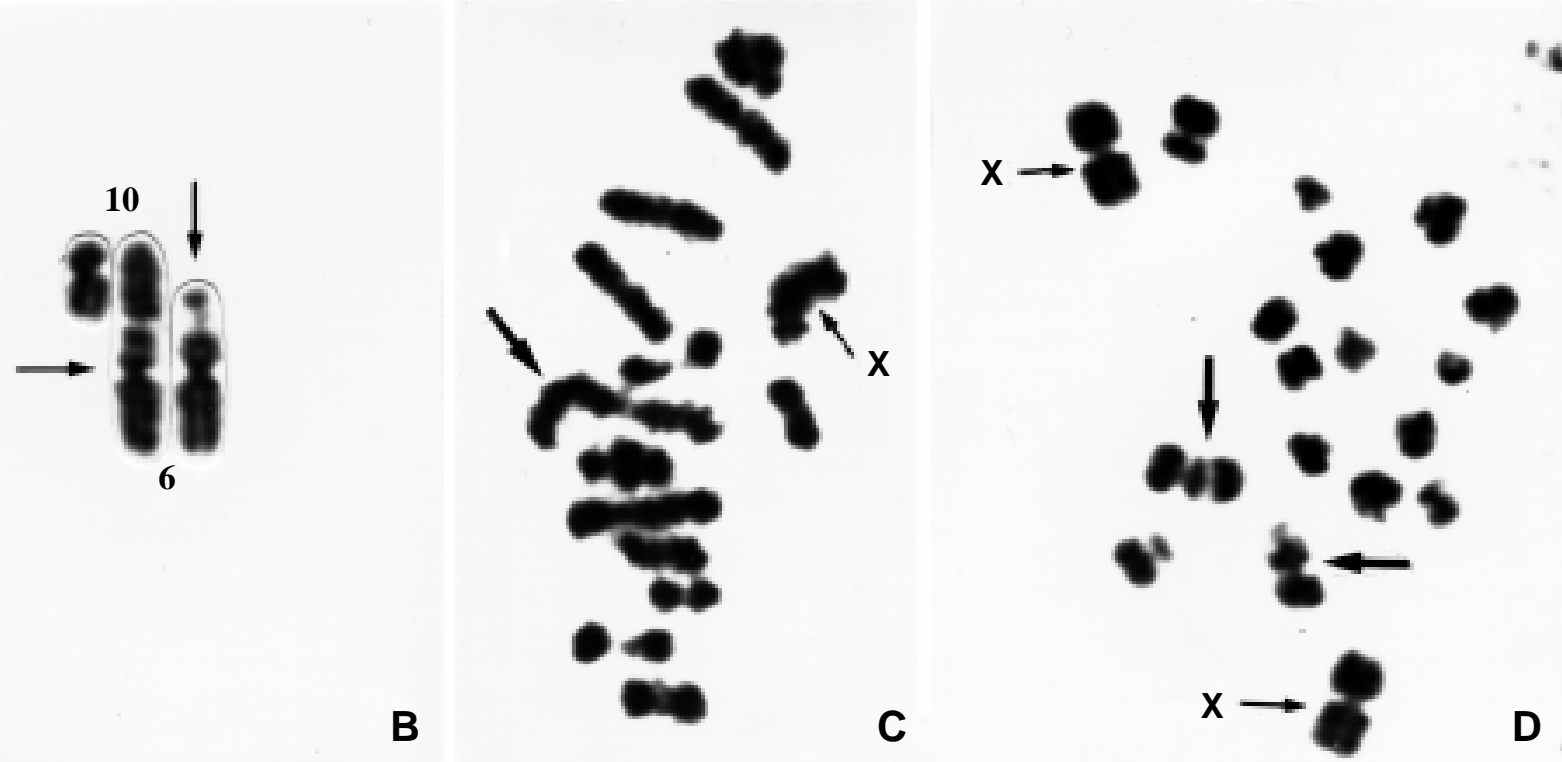

Figure 1 - Mitotic and meiotic chromosomes of Gryllus assimilis. A = Male karyotype 2n = 28, X0 with a heterozygous autosomal rearrangement, including homologous sixth and tenth chromosomes. $\mathrm{B}=$ Chromosomes involved in the autosomal rearrangement. The horizontal arrow shows the chromosome derived from the rearrangement bearing two secondary constrictions; its p-arm is probably homologous to chromosome 10. The vertical arrow indicates chromosome 6 with two secondary constrictions, and is homologous to the $\mathrm{q}$-arm of the rearranged chromosome. $\mathrm{C}=$ Metaphase $\mathrm{I}$ : arrow shows a trivalent. $\mathrm{D}=$ Uncompleted mitotic metaphases in a female. The arrows indicate elements involved in rearrangement. Bar in panel A corresponds to $10 \mu \mathrm{m}$.

In one of the non-rearranged individuals, there was considerable variation in the degree of chromosomal condensation and morphological structure of the secondary constriction in the sixth pair (Figure 2A-E).

\section{DISCUSSION}

The reduction in the number of chromosomes from $2 n=29$ to 28 in males and from $2 n=30$ to 29 in females, seen in the five specimens of G. assimilis examined, probably occurred by a tandem translocation between the sixth and tenth pairs of chromosomes (Figure 3C-E). For this to happen there would need to have been an initial pericentric inversion of one chromosome of the tenth pair, involving the transfer of a centromere to a sub-distal position (Figure 3A,C).

The tandem translocation took place between the satellite region of the small arm of the sixth pair and the centromeric end of the inverted tenth pair. The small chro- 


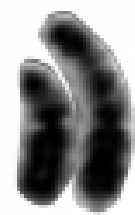

A

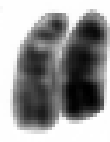

B

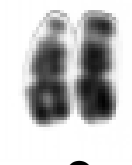

C

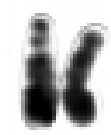

D

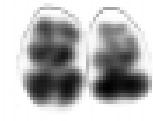

E

Figure 2 - Changes in the condensation and morphology of the arm bearing secondary constrictions in the sixth pair of chromosomes. A and $\mathrm{C}=$ Heteromorphic pairs. $\mathrm{B}, \mathrm{D}$ and $\mathrm{E}=$ Variation in homomorphic pairs.

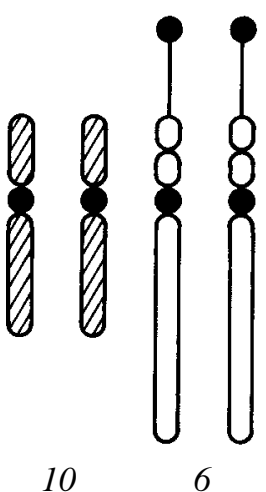

A

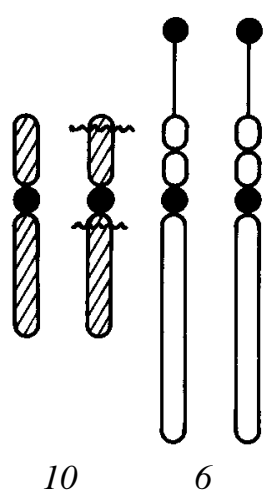

B

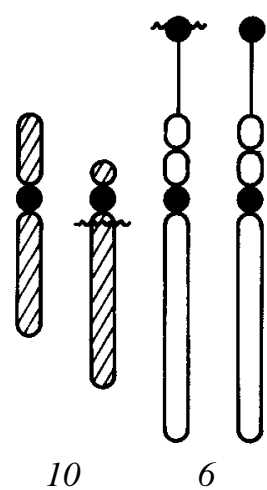

C

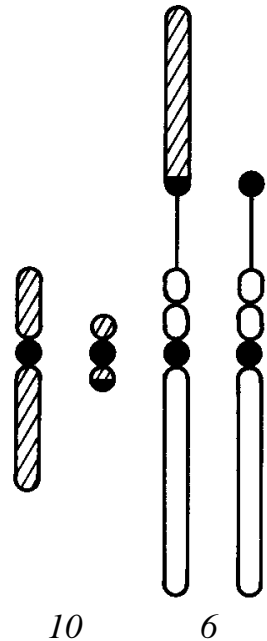

D

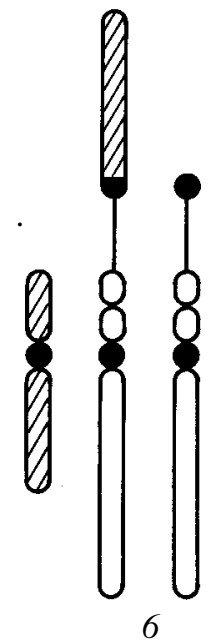

E

Figure 3 - Source of autosomal rearrangement. A = Chromosomes involved in rearrangement: the tenth submetacentric pair and the sixth submetacentric with constrictions in the short arm. B = Pericentric inversion in the tenth chromosome. C,D = Tandem translocation involving inverted chromosome of the tenth pair with the satellite from the short arm of sixth pair. E = Rearranged chromosomes showing a small submetacentric chromosome in the tenth pair, a large submetacentric chromosome with two secondary constrictions in the upper arm and a submetacentric chromosome with two constrictions in the lower arm. Small element is lost.

mosome resulting from the translocation (Figure 3D) had few or no genes and was therefore lost. The result of the translocation was a large, submetacentric chromosome with two secondary constrictions in the longest arm. During meiosis I, a trivalent was formed with the translocated chromosome going to one pole at anaphase I while the original chromosomes (sixth and tenth) went to the opposite pole.

A heteromorphism similar to the extension of the secondary constrictions found in G. assimilis was also reported by Lamborot and Alvarez Sarret (1985) in an unidentified species of Gryllus. These authors observed several variants in the length of the secondary constrictions as well as in the shape and size of the satellite. In this case, the length of the secondary constriction was determined by facultative inactivation of the homologous nucleolar organizers in a manner similar to that observed in the $\mathrm{G}$ group of human chromosomes (Orye, 1974).

Homologous chromosomes with heteromorphic secondary constrictions were observed by Zefa (1995) in three species of Gryllus and are also evident in the karyotypes of G. campestris and G. bimaculatus (Warchalowska-
Sliwa, 1980) and G. argentinus (Mafla and Cevallos, 1989). The heteromorphism of the constrictions in the chromosome arm could also reflect pretreatment with colchicine since this alkaloid induced changes in the degree of chromatin condensation. Different cells of the same tissue sometimes showed variable condensation, particularly among chromosomes with secondary constrictions (Figure 2A-E).

A autosomal polymorphism in crickets is relatively frequent (Mesa, A., personal communication) with the three most common karyotypes being: a) homozygous for the normal condition, b) homozygous for a rearrangement and c) heterozygous for a rearrangement. Homozygosity for a new rearrangement has not been found yet.

The rearrangement shown here is the only one described so far for the genus Gryllus.

\section{ACKNOWLEDGMENTS}

I thank Dr. Alejo Mesa for his suggestions and Mrs. Dayse F. de O. Carneiro for technical assistance. Research supported by CAPES and CNPq. Publication supported by FAPESP. 


\section{RESUMO}

A espécie Gryllus assimilis L. apresenta $2 \mathrm{n}=29, \mathrm{X} 0$ (macho) e $2 \mathrm{n}=30, \mathrm{XX}$ (fêmea), porém em alguns indivíduos coletados na cidade de Rio Claro, São Paulo, Brasil, foram encontrados dois cariótipos distintos: o cariótipo básico e outro rearranjado, com $2 n=28$, X0 e $2 n=29$, XX. O rearranjo foi interpretado como sendo autossômico e heterozigoto, caracterizado pela translocação envolvendo dois pares de homólogos submetacêntricos: o par 10, que possivelmente tem um dos elementos com uma inversão pericêntrica, e o par 6, que possui em seu braço curto duas constrições secundárias, diferenciando satélites em suas extremidades.

\section{REFERENCES}

Baumgartner, W.J. (1904). Some evidence for the individuality of the chromosomes. Biol. Bull. 8: 1-23.

Guerra, M.S. (1986). Reviewing the chromosome nomenclature of Levan et al. Rev. Bras. Genét. IX: 741-743.

Lamborot, M. and Alvarez-Sarret, E. (1985). The chromosomes of Gryllus field cricket populations in central Chile (Insecta: Grylloptera). Can. J. Zool. 63: 2626-2631.

Mafla, A.B. and Cevallos, V. (1989). The case of Gryllus argentinus in Ecuador: I. Cytogenetics. Evol. Biol. 3: 209-226.

Orye, E. (1974). Relative activation and inactivation phenomena between homologous and non homologous nucleolus organizers on the normal human 6 chromosome. Cytogenet. Cell Genet. 13: 352-368.

Warchalowska-Sliwa, E. (1980). Karyological observations on Gryllus spp. (Gryllidae, Orthoptera) 1. Karyotypes of Gryllus bimaculatus and Gryllus campestris. Folia Biol. 28: 187-194.

Weissman, D.B., Rentz, D.C.F., Alexander, R.D. and Loher, W. (1981). Field crickets (Gryllus and Acheta) of California and Baja California, Mexico (Orthoptera: Gryllidae: Gryllinae). Trans. Am. Ent. Soc. 106: 327-356.

Zefa, E. (1995). Bioacústica, citogenética, morfologia da asa e do complexo fálico de algumas espécies do gênero Gryllus (Orthoptera, Gryllidae) do Estado de São Paulo. Master's thesis, Instituto de Biociências, Universidade Estadual Paulista (UNESP), Rio Claro.

(Received July 31, 1998) 